\title{
Thermal Chamber for Adhesives Creep Multi-Station Testing Machine
}

\author{
Manuel Brito Janeira ${ }^{1}$, Carlos M. da Silva², António M. Lopes ${ }^{3}$, \\ Lucas F. M. da Silva ${ }^{4}$ \\ ${ }^{1}$ Department of Mechanical Engineering, Faculty of Engineering, University of Porto, Rua Dr. \\ Roberto Frias, 4200-465 Porto, Portugal (em10146@fe.up.pt) ORCID 0000-0001-5641-7997; \\ ${ }^{2}$ Department of Mechanical Engineering, Faculty of Engineering, University of Porto, Rua Dr. \\ Roberto Frias, 4200-465 Porto, Portugal (csilva@fe.up.pt) ORCID 0000-0002-2047-0873; \\ ${ }^{3}$ Department of Mechanical Engineering, Faculty of Engineering, University of Porto, Rua Dr. \\ Roberto Frias, 4200-465 Porto, Portugal (aml@fe.up.pt) ORCID 0000-0001-7359-4370; \\ ${ }^{4}$ Department of Mechanical Engineering, Faculty of Engineering, University of Porto, Rua Dr. \\ Roberto Frias, 4200-465 Porto, Portugal (lucas@fe.up.pt) ORCID 0000-0003-3272-4591
}

\begin{abstract}
Adhesives have been used in a wide range of industries, due to their good proprieties when compared with traditional joining methods. Therefore, manufacturers and researchers have been making an effort to study these materials and their characteristics.

The main goal of the Advance Joining Processes Unit (AJPU) of FEUP/INEGI is to study and evaluate different types of adhesives under different conditions. One equipment available at the AJPU is a creep testing machine with three independent working stations. As the creep tests must be performed under controlled temperature, the implementation of a thermal chamber was required.

This paper describes the design of a thermal chamber for the existing creep testing machine. The chamber needs to be capable of operating between -100 and $200{ }^{\circ} \mathrm{C}$ and have a low temperature gradient.

The first step was to design a heat insulator for each upper rod of the creep testing machine, in order to limit the temperature at the load cells to service values.

Subsequently, the concept of the chamber was developed. The design decisions with influence on the thermal efficiency of the chamber were supported analytically. The structure, insulation, control and automation projects of the chamber are presented in detail.
\end{abstract}

Author Keywords. Adhesive Performance, Creep Testing Machine, Thermal Chamber, Heat Insulator, Creep.

Type: Research Article

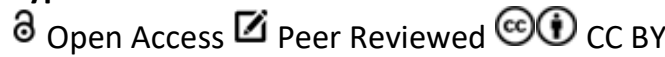

\section{Introduction}

Adhesives have an increasing importance in today's industry, with a strong presence in the aerospace, automotive, railway and marine industries, as well as in civil construction, electrical equipment, and even in medicine and dentistry areas (Borie et al. 2019; Faneco et al. 2017; Leggat, Smith, and Kedjarune 2007; Matta, Karbhari, and Vitaliani 2005; Takahashi et al. 2002). While the use of natural adhesives is very ancient, was only in recent years that stronger adhesives based on synthetic polymers were developed and used. The advantages of adhesive joints compared with traditional mechanical joints led to the increase of the studies in this field (Adams and Coppendale 1976; Banea et al. 2018; Beber, Schneider, and Brede 2019; Carbas, da Silva, and Andrés 2017; da Silva, Öchsner, and Adams 2011; Machado, Marques, and da Silva 2018; Sommer et al. 2016). 
The main goal of the Advanced Joining Processes Unit (AJPU) of FEUP/INEGI is to study and evaluate different types of adhesives under different conditions. An important equipment for evaluation of the behavior of adhesive joints is an in-house made multi-station creep testing machine. Creep behavior is a critical design parameter, especially for adhesives, which requires thorough study. Due to the correlation between creep and temperature, studying creep under different values of temperature is of paramount importance (Dowling 2012).

The main goal of this paper is to describe the development process of a thermal chamber that can operate between -100 and $200{ }^{\circ} \mathrm{C}$. The chamber will be integrated with an existing multistation creep testing machine depicted in Figure 1. It must guarantee human safe temperature values on the exterior casing, and safe temperature values for all the components that constitute the equipment. The chamber also needs to work autonomously, meaning that the temperature control has to be ensured over long periods of time without human intervention, and the interface for setting up the thermal conditions should be user-friendly.

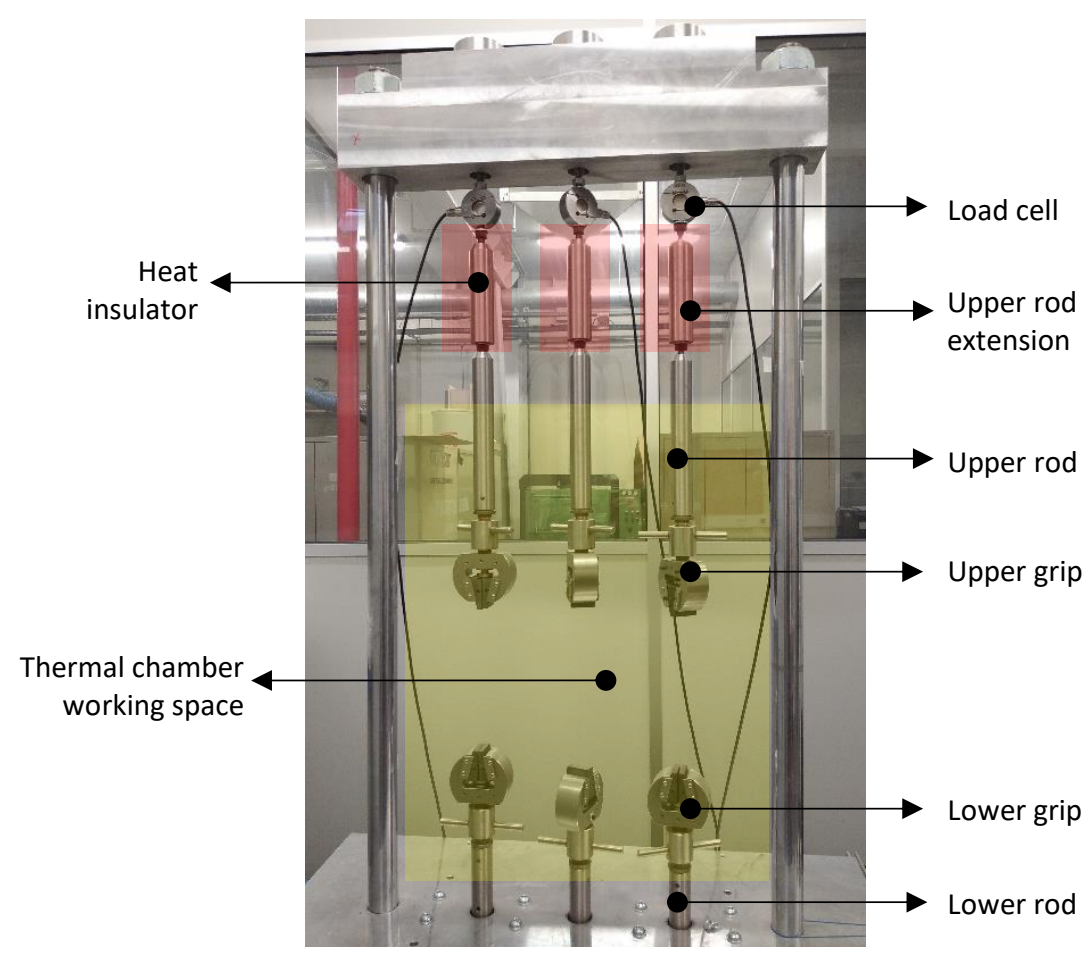

Figure 1: The AJPU creep testing machine

\section{Heat Insulator}

On the top of each rod of the creep machine a load cell is installed. These devices have an admissible range of temperature to operate between -10 and $+40{ }^{\circ} \mathrm{C}$. Therefore, it is necessary to create a heat insulator for protecting this equipment.

The concept of the heat insulator is illustrated in Figure 2. The heat insulator is constituted by a three-piece stainless-steel cylindrical casing, in which the bottom and top lids screw. Inside the casing, the bottom part of the modified upper rod extension is attached to a cylindrical base plate by two nuts (not represented in the figure). Between the base plate and the bottom lid of the casing, a ceramic insulator is lodged. On the top lid, the top part of the modified upper rod extension is attached. The empty space inside the casing is occupied by rock wool to avoid heat transfer by radiation and increase the insulation. 


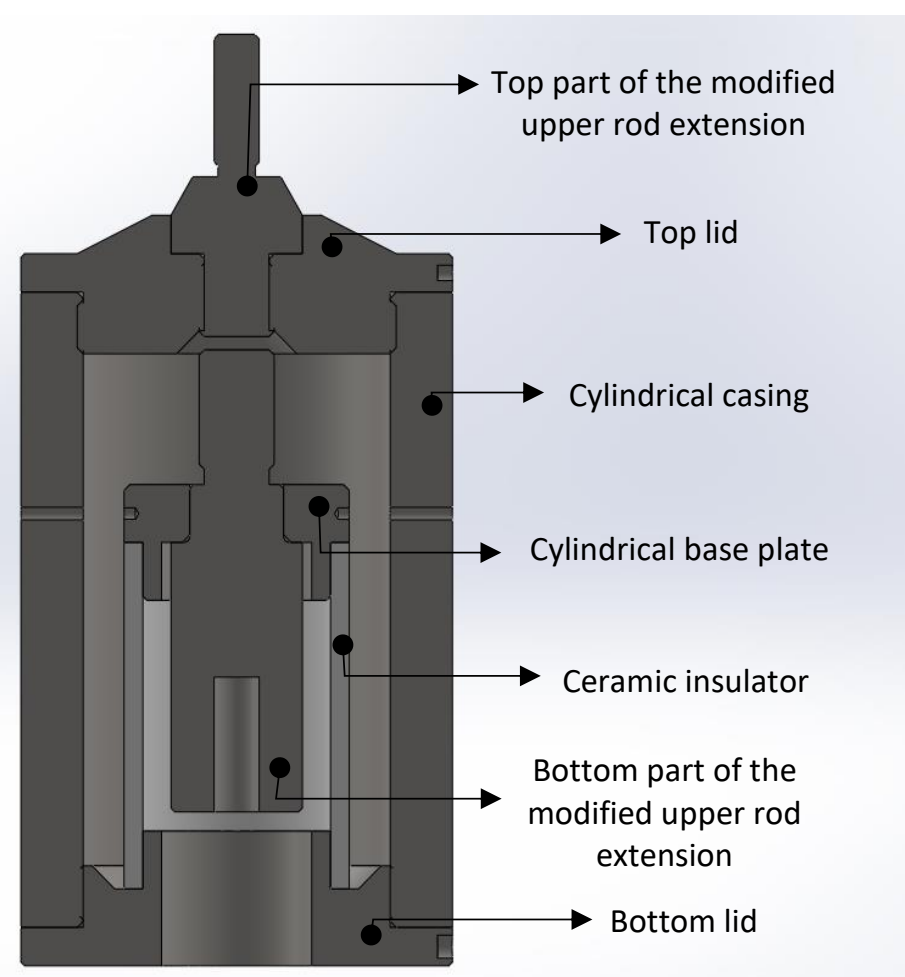

Figure 2: Mechanical design of the heat insulator

This configuration allows the required force transmission $(3.0 \mathrm{kN})$ for the creep test. A traction force is exerted on the bottom part of the modified upper rod extension, compresses the ceramic insulator and finally is transmitted to the bottom of the casing. The ceramic insulator must have a very low conduction coefficient, to minimize the heat flow that reaches the top of the casing and to have a compression stress that can withstand the forces applied by the creep testing machine. The material selected for the ceramic insulator was cordierite and its proprieties are described in Table 1.

\begin{tabular}{cc}
\hline Characteristic & Value \\
\hline Density & $1,600[\mathrm{~kg} / \mathrm{m} 3]$ \\
Elastic modulus & $120[\mathrm{GPa}]$ \\
Compressive strength & $600[\mathrm{MPa}]$ \\
Thermal conductivity & $1.3[\mathrm{~J} / \mathrm{m} \mathbb{K}]$ \\
Specific heat & $800[\mathrm{~J} / \mathrm{kg} \mathbb{K}]$ \\
Maximum service temperature & $1,300\left[{ }^{\circ} \mathrm{C}\right]$ \\
\hline
\end{tabular}

Table 1: Cordierite proprieties

To validate the design, several thermal simulations were run using the software SolidWorks ${ }^{\circledR}$. The first step was to define the thermal loads in terms of natural convection, radiation and conduction.

Evaluating the convection coefficient is not an easy task. The literature on the subject is vast and there are several equations that try to establish the best approximation to the reality. Therefore, utilizing the online tool from QuickField (QuickField 2019) that calculates the natural convection coefficient, and knowing that the Nusselt equation for a cylinder can be used for a vertical plane (Bergman et al. 2011), this value was obtained for the range of temperatures needed. A graph of the evolution of the coefficient for different temperatures was obtained, as shown in Figure 3. 


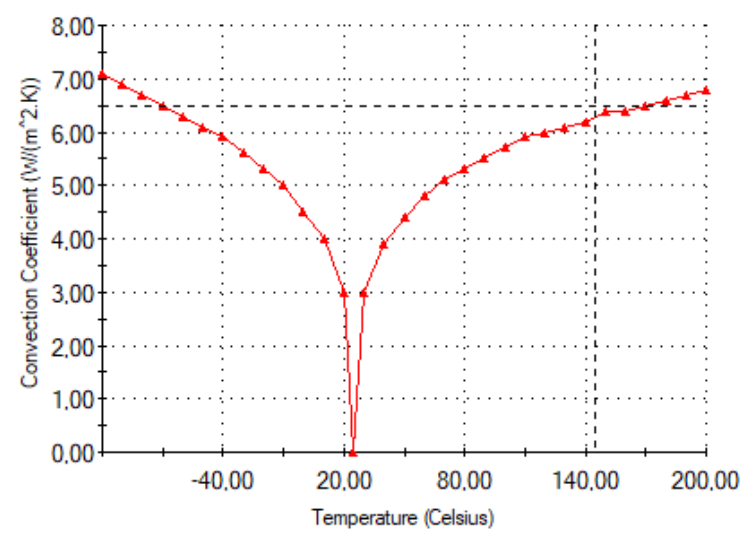

Figure 3: Graphic of the convection coefficient versus temperature

For the radiation of the casing to the exterior, a typical value of emissivity for stainless steel (0.4) was used. The room temperature was defined at $298 \mathrm{~K}$ and was also established a view factor of 1 . The conduction is directly computed by the software, based on the conductivity of each material that has been previously defined.

Two simulations were executed applying a temperature load of 200 and $-100{ }^{\circ} \mathrm{C}$ to the bottom part of the modified upper rod extension.
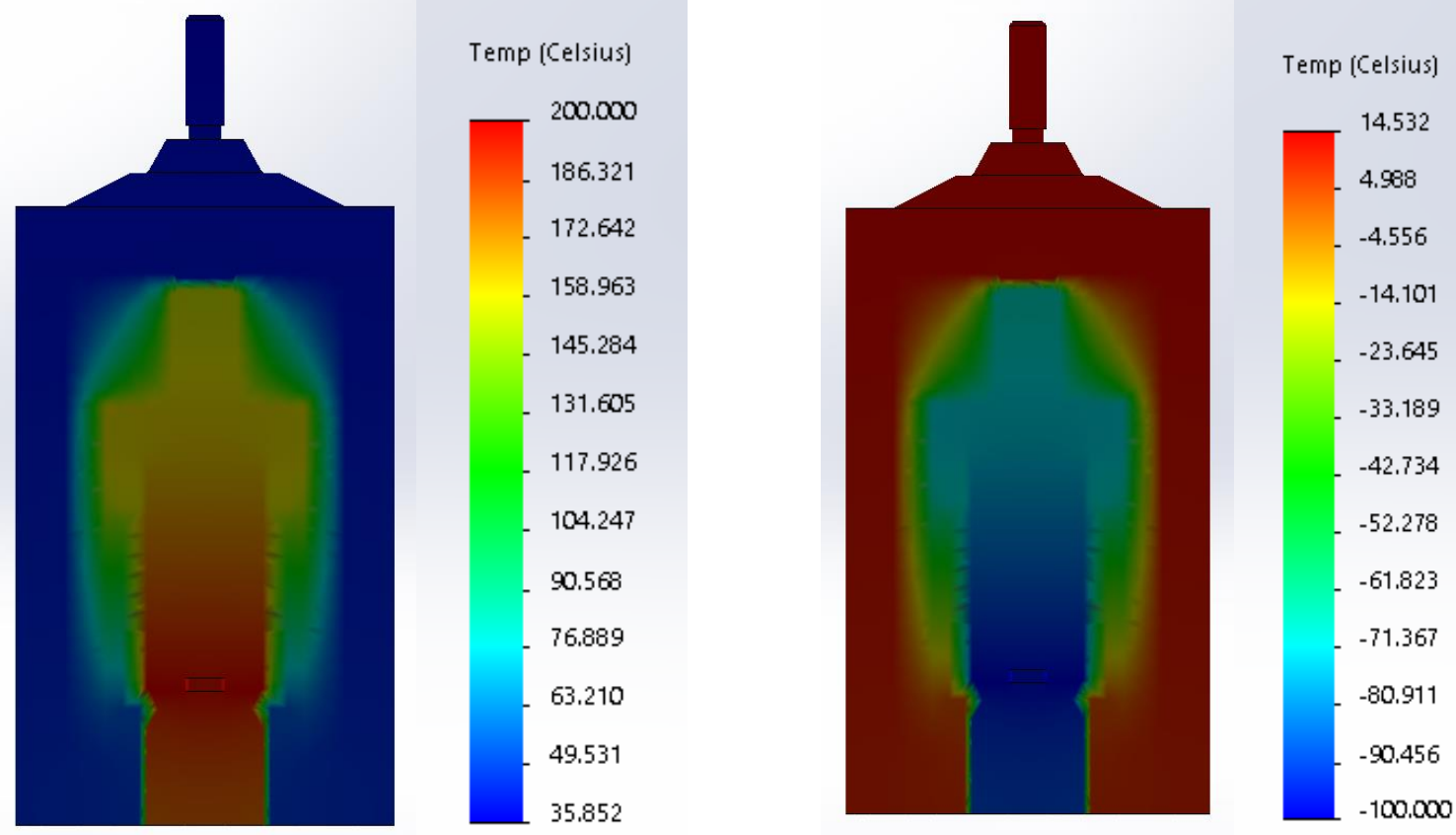

Figure 4: Results of the thermal simulations with a tempeartura load of $200{ }^{\circ} \mathrm{C}$ and $-100{ }^{\circ} \mathrm{C}$

Both the results obtained (Figure 4) after the thermal simulations showed the temperature in the nominal range of the load cells. The peak temperature values at the load cell were 35.9 for a $200{ }^{\circ} \mathrm{C}$ heating load, and 14.5 for a $-100{ }^{\circ} \mathrm{C}$ cooling load.

Complementarily, it is necessary to evaluate how the heat insulator behaves mechanically. For this purpose, a model was devised where the body was fixed by its threaded connection to the load cell, and a maximum static load of $3.0 \mathrm{kN}$ was applied to the connection rod. The results are shown in Figure 5. 

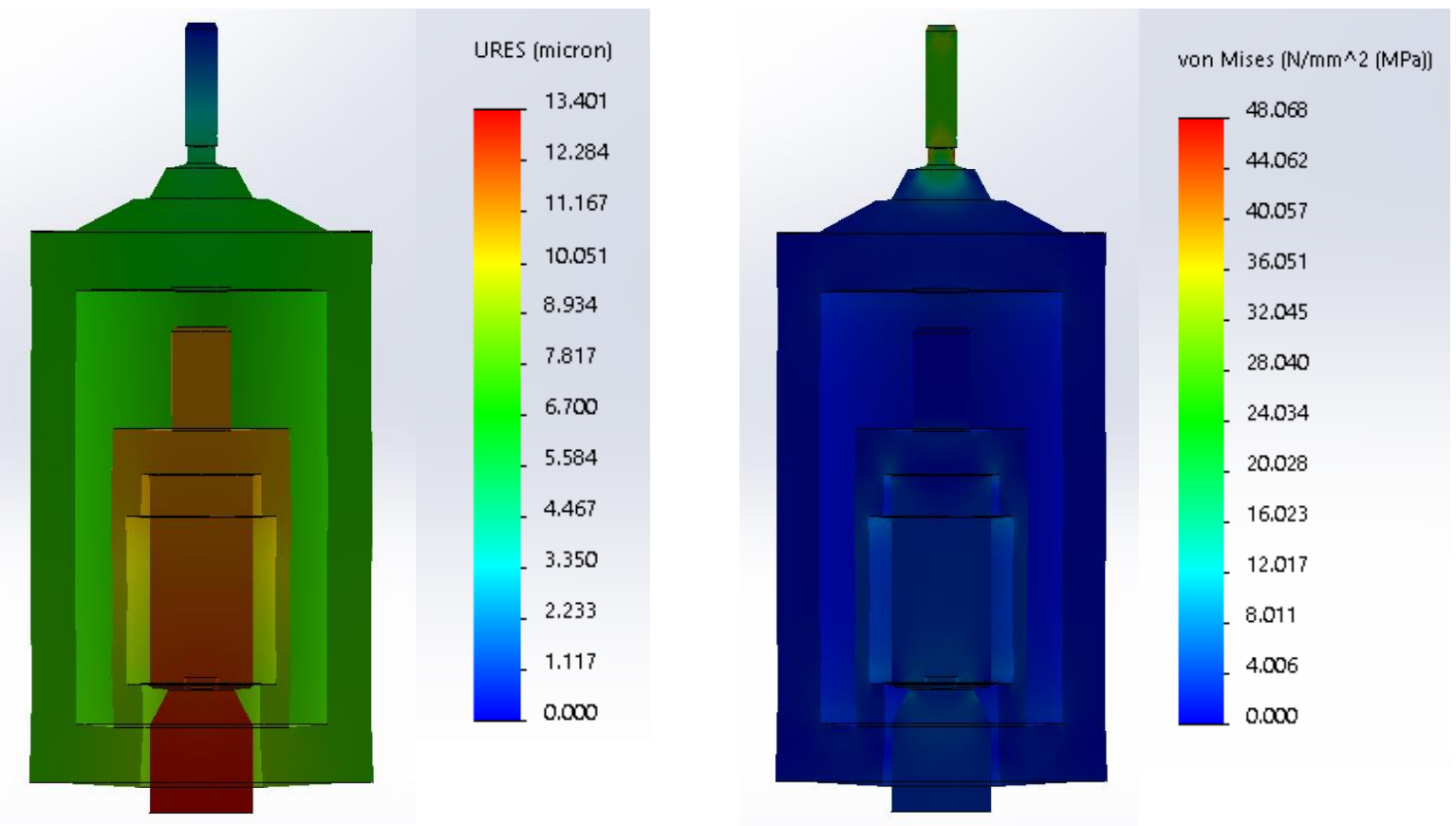

Figure 5: Results of the static load simulations

It can be verified that the maximum values of stress occur on the connection to the load cell, with a maximum value of $48.1 \mathrm{MPa}$, and the displacement values are also low (13.4 microns). These values are acceptable for the creep testing machine, with the results of all the simulations validating the design of the heat insulator.

\section{Thermal Chamber}

For the thermal chamber it was adopted a design in which the chamber is vertically split into two halves and can pivot around the columns of the creep testing machine with the help of a crank, as is shown in Figure 6. Three casings of $0.5 \mathrm{~mm}$ austenitic stainless steel sheets constitute each half of the chamber. Stainless-steel was used due to its corrosion resistance and low thermal conductivity. When assembled, the casings create two insulations layers. The layer closer to the inner volume of the chamber is filled with rock wool, in order to preserve the heat. Inside the second layer, an air flow is created by two fans installed in the back half of the chamber. This layer ensures a reduction of the temperature in the outer casing to human safe values. To guarantee that the air flows freely through both halves, additional slots were made on the front frame of each half, and slots in front half of the chamber for the exhausting of the air to the atmosphere were also made. In the middle casings, structural profiles were attached to give stiffness to the chamber.

A window was designed in the front side of the chamber, allowing the visualizations of the specimens under test. In order to create a rigid frame to mount the glass panels and the window spacers, stainless-steel angles were placed around the opening of the window. Then smaller stainless-steel angles were glued to the first angle, creating a surface where the rest of the components can lean on. Between the outer glass panel and the angle a rubber band to seal the window was included. After the first glass panel there is a window spacer followed by another glass panel. There is one more window spacer and one glass panel, before another stainless-steel angle is used to holds all the components together. A rigid frame is thus created, over which $5 \mathrm{~mm}$ stainless sheet is placed around the window interior frame. 


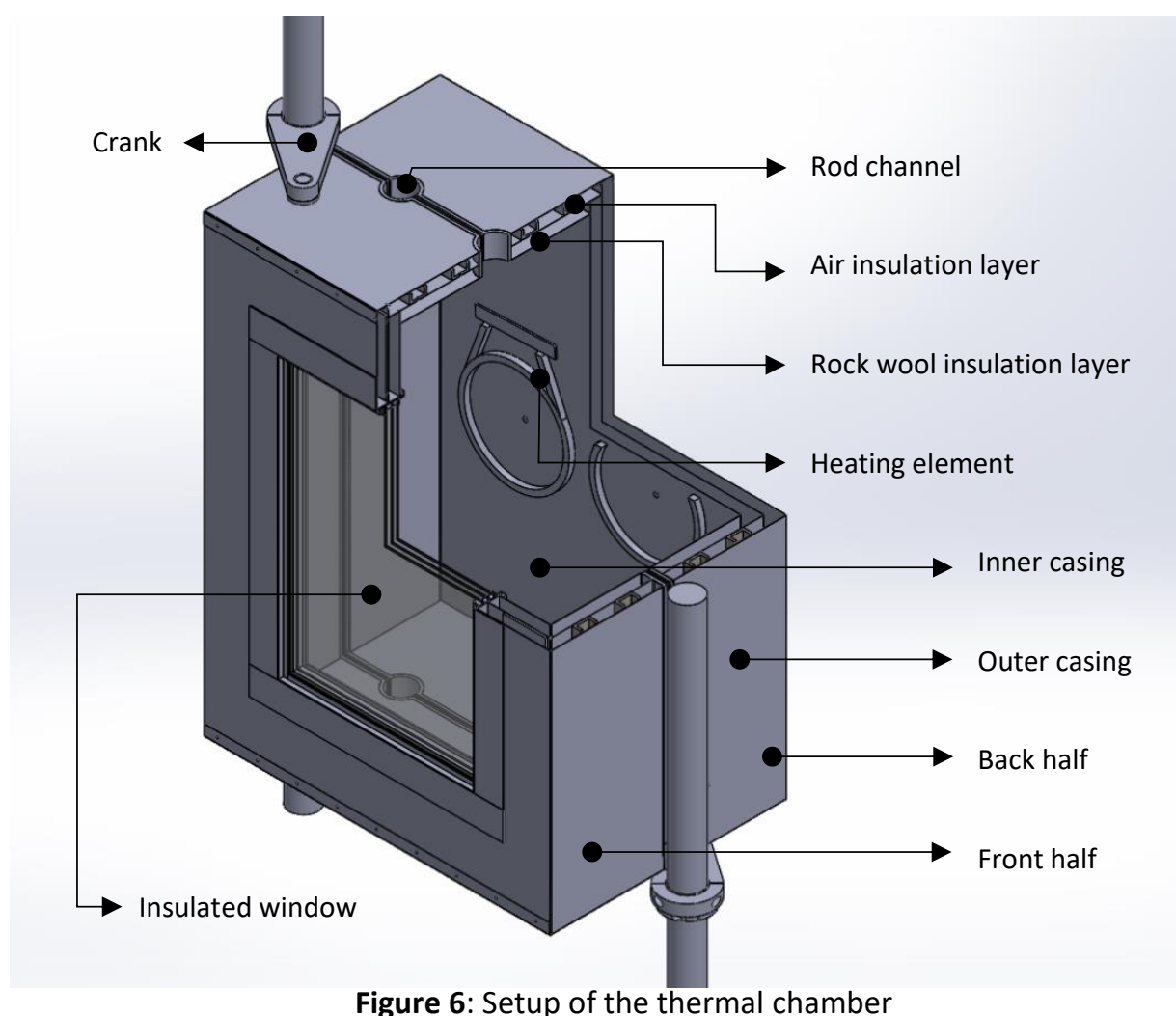

The chamber uses forced convection to spread the heated air or the coolant, accelerating the heat transfer process and ensuring a more homogenous temperature inside the chamber. This is accomplished with two fans in the inner volume (not represented in the figure).

For heating, two heating elements (electrical resistances) of $2500 \mathrm{~W}$ each are mounted. For cooling, a cryogenic coolant is injected in the test volume and exhausted through a hole in the back half of the chamber.

During the design of the chamber, a length of $20 \mathrm{~mm}$ was established for each insulation layer. This value was defined due to its convenience for the design, and also having in mind the thermal insulation. To verify if the values of the length of the insulation layers are acceptable, a simple analysis was made, resorting to the concept of thermal resistance. The equation for the thermal resistance in conduction is (Bergman et al. 2011).

$$
r_{\text {cond }} \equiv \frac{\Delta T}{q_{x}^{\prime \prime}}=\frac{L}{k}
$$

where $r_{\text {cond }}$ is the thermal resistance for conduction, expressed in $\mathrm{m}^{2} \mathbb{K} / \mathrm{W}, \Delta T$ is the difference of temperature between two points, expressed in $\mathrm{K}$, and $q_{x}^{\prime \prime}$ is the conduction heat flux, expressed in $\mathrm{W} / \mathrm{m}^{2}$. The thermal conductivity is represented by $k$, expressed in $\mathrm{W} / \mathrm{m} \mathbb{K}$ and $L$ is the length of the material, expressed in meters. The equation for the thermal resistance for convection is (Bergman et al. 2011).

$$
r_{\text {conv }} \equiv \frac{\left(T_{\infty}-T_{s}\right)}{q^{\prime \prime}}=\frac{1}{h}
$$

where $r_{\text {conv }}$ is the thermal resistance for convection, expressed in in $\mathrm{m}^{2} \mathbb{\mathbb { K }} / \mathrm{W},\left(T_{\infty}-T_{s}\right)$ is the difference of temperature between the fluid and surface, expressed in $\mathrm{K}$, and $q^{\prime \prime}$ represents the convection heat flux, expressed in $\mathrm{W} / \mathrm{m}^{2}$. The convection coefficient is represented by $h$ and is expressed in $\mathrm{W} / \mathrm{m}^{2} \mathbb{K}$ 
To calculate the heat flux transfer through the walls of the chamber it is possible to associate all the thermal resistances, thus obtaining the total heat flux transfer to the outside of the chamber, given by

$$
q^{\prime \prime}=\frac{\Delta T}{\sum r}
$$

where $\Sigma r$ is the sum of all the thermal resistances. Dividing the heat flux by the total area of the chamber, the heat transfer rate is obtained, which is the transfer of heat from the chamber to its surroundings.

The conductivity of the materials in the insulation layers and the convection coefficient of the air are represented in Table 2.

\begin{tabular}{ccc}
\hline & Characteristic & Value \\
\hline Stainless steel & Conductivity & $16[\mathrm{~W} / \mathrm{m} \mathbb{K}]$ \\
Rock wool & Natural convection coefficient & $0.04[\mathrm{~W} / \mathrm{m} \mathbb{K}]$ \\
Air & $5[\mathrm{~W} / \mathrm{m} 2 \mathbb{K}]$ \\
& Forced convection coefficient & $100[\mathrm{~W} / \mathrm{m} 2 \mathbb{K}]$ \\
\hline
\end{tabular}

Table 2: Parameters used for calculating the thermal resistances of the chamber

The equation used to calculate the heat transfer rate is

$$
q=\frac{\Delta T}{\frac{1}{A} \cdot\left(\frac{1}{h_{e}}+3 \frac{L_{s}}{k_{s}}+\frac{L_{r}}{k_{r}}+2 \frac{1}{h_{i}}\right)}
$$

where $q$ represents the heat transfer rate, expressed in $\mathrm{W}$ and $\Delta T$ is the difference of temperature between the chamber at its maximum value $\left(200^{\circ} \mathrm{C}\right)$ and $\mathrm{RT}\left(\approx 25^{\circ} \mathrm{C}\right)$. The total area of the chamber is represented by $A$, expressed in $\mathrm{m}^{2}$. The exterior convection coefficient is represented by $h_{e}$ and the internal on by $h_{i}$, both expressed in $\mathrm{W} / \mathrm{m}^{2} \mathbb{\mathbb { K }}$ The conductivity of the stainless sheets and of the rock wool are represented by $k_{s}$ and $k_{r}$, respectively, and are expressed in $\mathrm{W} / \mathrm{m} \mathbb{K}$ The length of the sheets and the rock wool are expressed in meters and are represented by $L_{s}$ and $L_{r}$ (Bergman et al. 2011).

Oversized dimensions for the chamber were considered in the calculations in order to ensure an acceptable value of heat transfer to its surroundings. Thus, the dimensions assumed for the chamber were $810 \mathrm{~mm}$ in height, $610 \mathrm{~mm}$ in width and $420 \mathrm{~mm}$ in depth, resulting in a total area of $2.181 \mathrm{~m}^{2}$. The calculated heat transfer rate is about $530 \mathrm{~W}$, being this value a little bit more than $10 \%$ of the power of the heating elements. Meaning that $10 \%$ of the heat used to reach the maximum values of temperature in the chamber is transferred to the atmosphere. A $10 \%$ loss is acceptable, which validates the size of the insulation cases.

The surface of the window was ignored in the previous calculations. Thus, it is necessary to calculate the heat flux that occurs through the window and compare it with the heat flux that occurs when there is no window. To calculate the heat flux that goes through the window, Equation 3 was considered. The parameters used to obtain the thermal resistances are represented in Table 3 . The thickness of the glass is $3 \mathrm{~mm}$ and between each glass panel there is an air case of $7.5 \mathrm{~mm}$.

\begin{tabular}{ccc}
\hline & Characteristic & Value \\
\hline Glass & Conductivity & $1.6[\mathrm{~W} / \mathrm{m} \mathbb{K}]$ \\
& Conductivity & $0.023[\mathrm{~W} / \mathrm{m} \mathbb{K}]$ \\
\multirow{2}{*}{ Air } & Natural convection coefficient & $5[\mathrm{~W} / \mathrm{m} 2 \mathbb{K}]$ \\
& Forced convection coefficient & $100[\mathrm{~W} / \mathrm{m} 2 \mathbb{K}]$ \\
\hline
\end{tabular}

Table 3: Parameter used for calculate the thermal resistances of the window

The calculated heat flux obtained was $146.6 \mathrm{~W} / \mathrm{m}^{2}$. Previously, it was said that the heat power rate was $530 \mathrm{~W}$ and the total area of the chamber was $2.181 \mathrm{~m}^{2}$. Therefore, dividing the heat 
power rate by the area, the value $243 \mathrm{~W} / \mathrm{m}^{2}$ of heat flux that goes through the chamber is obtained. Comparing the two values of the heat flux, it was concluded that the window does not add any heat losses to the exterior, validating its design and materials.

\section{Control and Command}

For controlling the temperature in the thermal chamber, the following elements are used:

- Industrial temperature controller;

- Cooling and heating elements;

- Interface temperature controller/cooling and heating elements;

- Temperature sensor.

The temperature sensor selected was a thermocouple type $T$ that has a temperature range between -270 and $400{ }^{\circ} \mathrm{C}$ (Powell et al. 1974). This temperature sensor was defined, since it has a measurement range compatible with the needs of the chamber, has high resistance to shock and vibrations, and has a fast thermal response.

As previously mentioned, heating elements are used to heat the thermal chamber. Those will be controlled by means of a commercial temperature controller that uses time-proportional control to emulate a PID. This is accomplished by switching a relay at high frequency. Therefore, a solid-state relay (SSR) is used to endure the number of commutations when commanding the heating elements. The cooling of the chamber uses a cryogenic coolant, a safety valve, and a cryogenic solenoid valve to control the injection of the coolant in the chamber. In addition, two pairs of fans operate in the chamber. One pair ensures that air flows through one of the insulation layers, and the other pair, assembled in the inner volume of the chamber, guarantees the homogeneity of the temperature inside the chamber.

The temperature controller receives a temperature set point from the user and information about the real temperature in the chamber, measured by the thermocouple. Based on these data and some suitable control law, it generates a control action that is then applied to the heating or cooling element, as depicted in Figure 7.

Thermal chamber

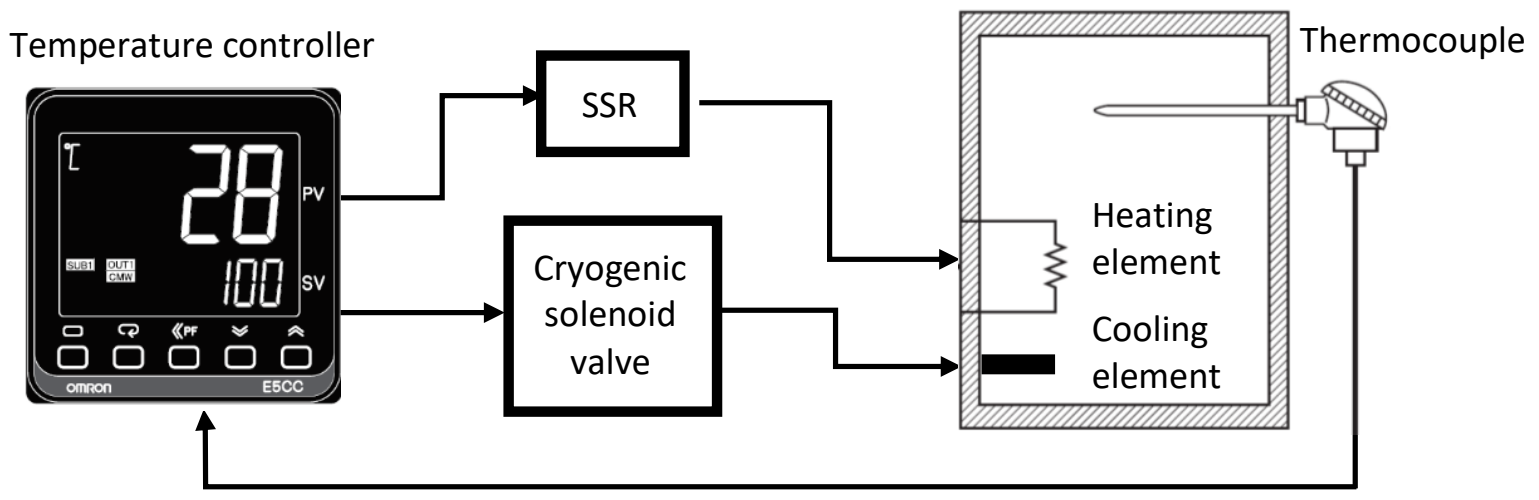

Figure 7: Scheme of the main components of the temperature control system

\section{Conclusions}

Although the use of structural adhesives has in increased greatly, the market demand for thermal chambers for multi-station creep testing machines is still very low. Therefore, the few commercial solutions on offer are expensive and not suitable for models different from those they commercialize. This raised the need for designing a thermal chamber for the threestation creep testing machine of the AJUP. 
To prevent the load cells from operating above its service temperature, heat insulators were designed and the necessary materials selected. The validation of these devices was based on thermal and mechanical static simulations, performed in the software SolidWorks ${ }^{\circledR}$.

The thermal chamber was designed for the existing creep testing machine. Its configuration allows each half to pivot around the columns of the machine and clear the test area. Its dimensions and material were supported analytically. Finally, the temperature control system and its components were defined.

\section{References}

Adams, R. D., and J. Coppendale. 1976. "Measurement of the elastic moduli of structural adhesives by a resonant bar technique". Journal of Mechanical Engineering Science 18, no. 3 (june): 149-58. https://doi.org/10.1243/JMES_JOUR_1976_018_025_02.

Banea, M. D., M. Rosioara, R. J. C. Carbas, and L. F. M. da Silva. 2018. "Multi-material adhesive joints for automotive industry". Composites Part B: Engineering 151 (october): 71-77. https://doi.org/10.1016/j.compositesb.2018.06.009.

Beber, V. C., B. Schneider, and M. Brede. 2019. "Experimental investigation and numerical prediction of static strength and fracture behaviour of notched epoxy-based structural adhesives". International Journal of Adhesion and Adhesives 93 (september): 32-39. https://doi.org/10.1016/j.ijadhadh.2019.01.023.

Bergman, T. L., F. P. Incropera, D. P. DeWitt, and A. S. Lavine. 2011. Fundamentals of heat and mass transfer. John Wiley \& Sons.

Borie, E., E. Rosas, G. Kuramochi, S. Etcheberry, S. Olate, and B. Weber. 2019. "Oral applications of cyanoacrylate adhesives: A literature review". BioMed Research International. Article number 8217602. https://doi.org/10.1155/2019/8217602.

Carbas, R. J. C., L. F. M. da Silva, and L. F. S. Andrés. 2017. "Functionally graded adhesive joints by graded mixing of nanoparticles". International Journal of Adhesion and Adhesives 76 (july): 30-37. https://doi.org/10.1016/j.ijadhadh.2017.02.004.

da Silva, L. F., A. Öchsner, and R. D. Adams, eds. 2011. Handbook of adhesion technology. Springer Science \& Business Media.

Dowling, N. E. 2012. Mechanical behavior of materials: Engineering methods for deformation, fracture, and fatigue. Pearson.

Faneco, T. M. S., R. D. S. G. Campilho, F. J. G. Silva, and R. M. Lopes. 2017. "Strength and fracture characterization of a novel polyurethane adhesive for the automotive industry". Journal of Testing and Evaluation 45, no. 2: 398-407. https://doi.org/10.1520/jte20150335.

Leggat, P. A., D. R. Smith, and U. Kedjarune. 2007. "Surgical applications of cyanoacrylate adhesives: A review of toxicity". ANZ Journal of Surgery 77, no. 4 (april): 209-13. https://doi.org/10.1111/j.1445-2197.2007.04020.x.

Machado, J. J. M., E. A. S. Marques, and L. F. M. da Silva. 2018. "Adhesives and adhesive joints under impact loadings: An overview". The Journal of Adhesion 94, no. 6 (may): 421-52. https://doi.org/10.1080/00218464.2017.1282349.

Matta, F., V. M. Karbhari, and R. Vitaliani. 2005. "Tensile response of steel/CFRP adhesive bonds for the rehabilitation of civil structures". Structural Engineering and Mechanics 20, no. 5 (july): 589-608. https://doi.org/10.12989/sem.2005.20.5.589.

Powell, R. L., W. J. Hall, C. H. Hyink Jr, L. L. Sparks, G. W. Burns, M. G. Scroger, and H. H. Plumb. 1974. Thermocouple reference tables based on the IPTS-68. NBS-MN-125. Washington DC, USA: US National Bureau of Standards. 
QuickField. 2019. "Natural convection coefficient calculator". https://quickfield.com/natural_convection.htm.

Sommer, S., T. Probst, E. Kraus, B. Baudrit, G. E. Town, and M. Koch. 2016. "Cure monitoring of two-component epoxy adhesives by terahertz time-domain spectroscopy". Polymer Science - Series $B$ 58, no. 6 (november): 769-76. https://doi.org/10.1134/s1560090416060154.

Takahashi, A., Y. Sato, S. Uno, P. N. R. Pereira, and H. Sano. 2002. "Effects of mechanical properties of adhesive resins on bond strength to dentin". Dental Materials 18, no. 3 (may): 263-68. https://doi.org/10.1016/S0109-5641(01)00046-X. 